\title{
Design of Administration System in Client Side Using Oracle Form Builder
}

\author{
Ghusoon Idan Arb \\ Assist.Lecturer Computer Engineering Dept.,University of Mustansiriyah,Baghdad \\ eng.computer38@gmail.com
}

\begin{abstract}
This paper focuses on the creation of a single system for distribution to a team of developers. Oracle Form Builder are popular and made the function of project expansion easier and comparably faster to reduce costs and improve service levels for users. Design of administration system in client side is made available to employees to assist them in the performance of their job duties. Both Oracle Database and MySQL are strong relational database management systems that effectively run great amounts of data. Oracle Database is a full distinct database engine that has successfully passed severe security exams and has excelled in performance benchmarks. With built-in backup for PL/SQL and Java. Oracle focusing on Java for next generation commerce applications.
\end{abstract}

\section{Indexing terms/Keywords}

Oracle Form Builder. Administration System.

\section{Academic Discipline And Sub-Disciplines}

Computer Science;

\section{SUBJECT CLASSIFICATION}

Graphical User Interface (GUI), Relational Database Management System (RDBM).

\section{INTRODUCTION}

This paper focuses on the creation of a single enterprise for distribution to a team of developers. In the range of security, the popularization and application of Internet, communications and computer connection technology has been quick development, , work and live[I]. In this paper we distinguish The System Global Area (SGA) and other memory areas, Database related files, Database concerning background processes, Table spaces and Data files, the instance and the database. Database instance has many background processes based on configuration. System Global Area is shared memory for SMON, PMON, DBWR, LGWR, ARCH, RECO, etc. Recovery Manager (RMAN) supports spicy backups and action as a separate central repository for manifold Oracle database servers.

\section{The Oracle Security Model}

we divide the checking of the components of an Oracle system into two master regions -Oracle operating system files (the physical entities) and Oracle database objects (the logical entities). A basic database security system, an audit system, and a user account repair application. Oracle supply highly clarify grained authorization controls to end system access. intercepting access should inclusive apply ing the principal of lower privilege. [ I].

\section{ADMINISTRATION SYSTEM ARCHITECTURE}

The architecture that oracle has built its database about is prepared to execute quickly, efficiently and without mistakes see figure(1):

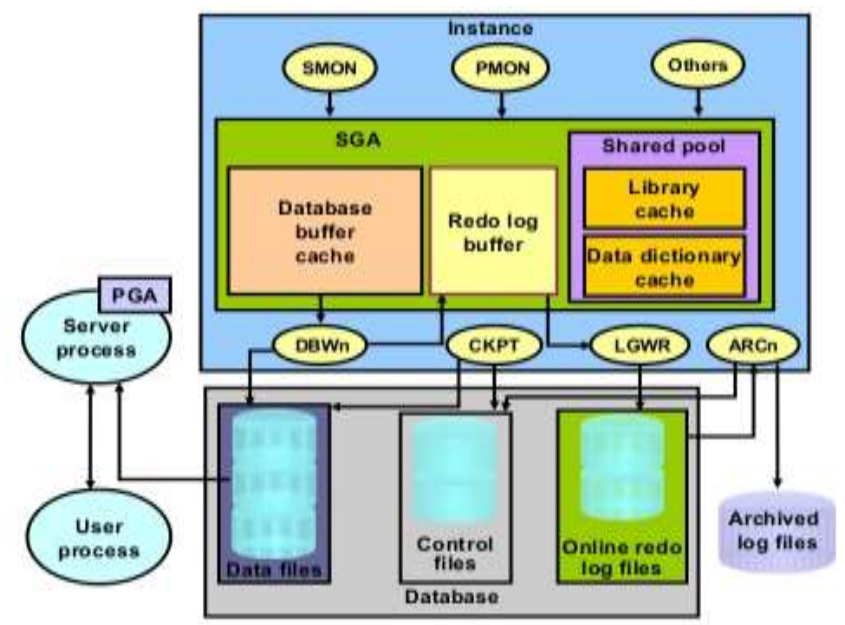

Fig 1: Database Architecture 


\section{Oracle Memory Structure}

The memory structure means sorting of logical memory for many processes of oracle see figure (2). The memory structures with Oracle Database include: System global area (SGA) and Program global area (PGA). SGA is a collection of common memory, known as SGA strains, that comprise data and control files for one Oracle Database instance. paradigms of data stored in the SGA contain cached data blocks and common SQL regions. A PGA is a not common memory region that contains data and control files exclusively for use by an oracle operation The PGA is formed by Oracle Database when an oracle operation is initiated [II].

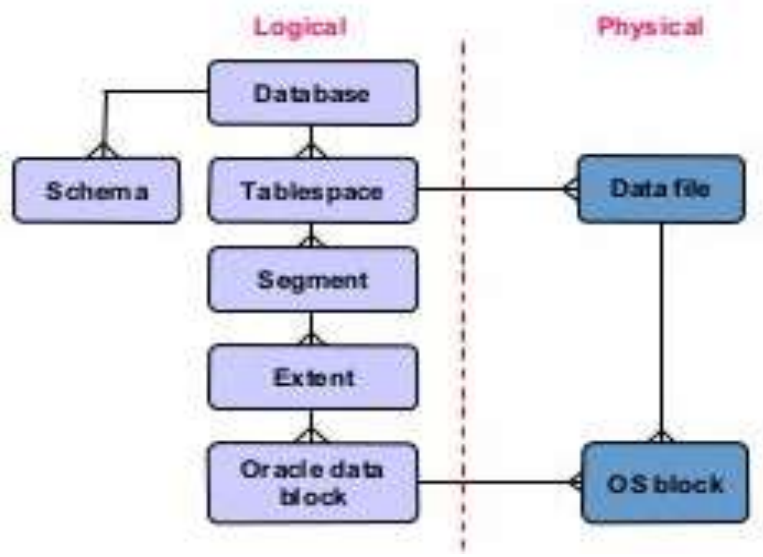

Fig 2: Memory Structure

\section{Client / Server System}

Oracle network services dealing with network connexions from a client or middle-tier implementation to the server. After a network hearing is instituted, oracle network acts as the data messenger for both the client and the server. It is accountable for foundation and repairing the link between the client and server, as well as substitute data between them. oracle network such as Java Database Connectivity (JDBC), is existing on each pc that necessarily for talking to the server. On the client ,oracle net is a background component accessed by whatever program needs connecting to the database such as oracle forms. The client not sees oracle network, simply the program that is using it. On the server, oracle network includes an quick operation called the listener. The oracle network listener is dependable for coordinating connexions between the database and foreign programs. Without the listener, foreign connexions to the database are impossible. While the most collective use of oracle network is allowing arrivals database communications, services also can be configured for allowing enter to foreign program libraries and commands and connecting, see figure(3)[ [III].

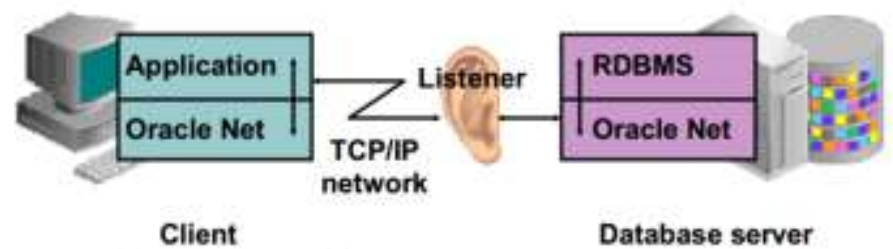

Fig 3:Client/ Server Connection

\section{CREATING AN EMPLOYEE SELF-SERVICE REQUESTOR FORM}

In figure (4) show employees table consist of :

1. employees_id, type of data in number and the number of character(6).

2. First name, type of data in varchar2 and the number of character(20).

3. Last name, type of data in varchar2 and the number of character(25).

4. Email ,type of data in varchar2 and the number of character(25).

5. Phone number, type of data in number and the number of character(20).

6. Hair_date, type of data not null enable.

7. Job_id, type of data in varchar2 and the number of character(10).

8. salary, type of data in number and the number of character(8).

9. commission_pct, type of data in number and the number of character(2).

10. manager_id, type of data in number and the number of character(6).

11. department_id, type of data in number and the number of character(4).
7157 | $P$ a g $\mathrm{e}$
council for Innovative Research 
International Journal of Computers \& Technology

\begin{tabular}{|c|c|c|c|c|c|c|c|c|c|}
\hline BQDE:D | F⿻上丨 & ti W. & 30 & I Hot,ues & 93 & ( 0,5 & Q中e? & 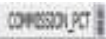 & Rowes & veuner is \\
\hline 18taticss & teter & in & nustess & 2ute: & स्वस्र & 28 & |zal| & 22 & 5) \\
\hline Iy:ath & and & uth & masties & 1⿴囗十 & Hotri & wo & |ritis & 22 & $\mathrm{~s}$ \\
\hline mats. & $\operatorname{aec}$ & त्राय & nyastes & 1040 & D1 153 & 46 & |mit| & 욤 & $\pi$ \\
\hline ttats & Ists & Et:5t! & 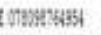 & motets & gys & 110 & |vilis & wo & ts \\
\hline thou & fasd & $\mathrm{HE}$ & mansan & 9vitut & nin & $\omega$ & |alli| & 211 & u \\
\hline Wratar & fint & 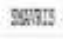 & mxarมาร & onem & $B \mathrm{~m}$ & 65 & inili? & 214 & 4) \\
\hline 2tisth & atti & EE: & 07tus3as & tititeld & tits & twot & |aiti) & 114 & $\pi$ \\
\hline 2listumses & ane & क्स:115 & 3 nosweis: & stict: & $\mathrm{k}, \mathrm{s}$ & $12 \mathrm{x}$ & |milis & 211 & $m$ \\
\hline Uteatat & catit & Fint & Magrost & wowe & 1.20x & $m$ & |xilal & w & 14 \\
\hline Imesilut & Inets. & $\operatorname{men}$ & mathas & stites & $\mathrm{B}$. & ane & fentif & (2at:1 & n \\
\hline Hiner & Palis & एक्डs: & 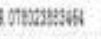 & that & 218 & $10 x$ & |ritis & $w$ & y \\
\hline Hener & LI & 그료 & ตาบละงแ & wet: & 1218 & $10 x$ & |riili & $2 x$ & y \\
\hline Whase & tatis & 150ing & 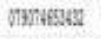 & swerds & $\pi m x$ & wo & (malli) & 12 & B \\
\hline Ithenest: & int & सESI & nogistat & 215 & $\pi \mathrm{ax}$ & $6 x$ & |ant| & w & e \\
\hline w5:kt & thisat & WWEt! & meinat: & 25/4t/ & $\pi \mathbb{B} x_{6}$ & 48 & |mit| & 28 & क \\
\hline
\end{tabular}

Fig 4: Employees Table

In figure (5) and figure(6) show many tasks are designed in oracle form builder such as query, insert, delete records as GUI.

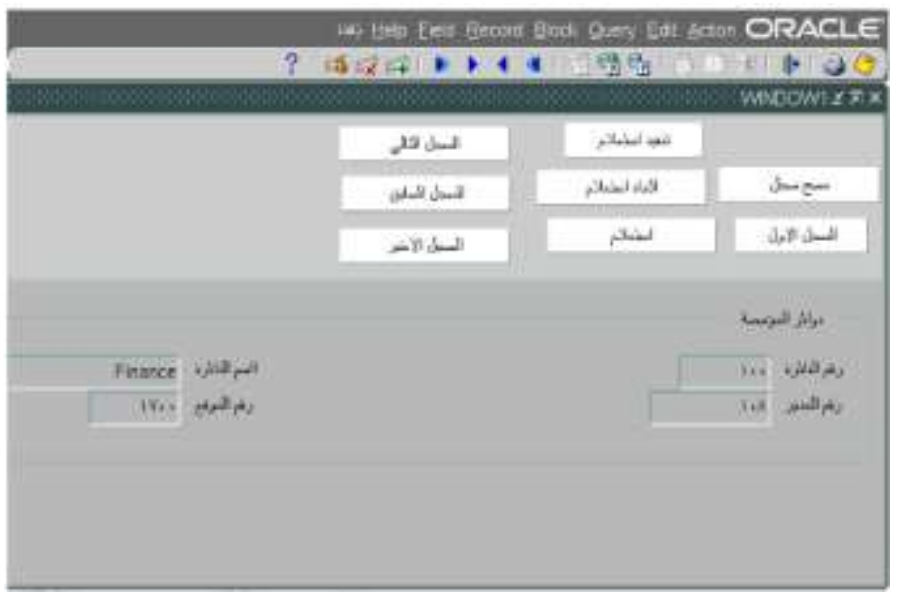

Fig 5: Administration System

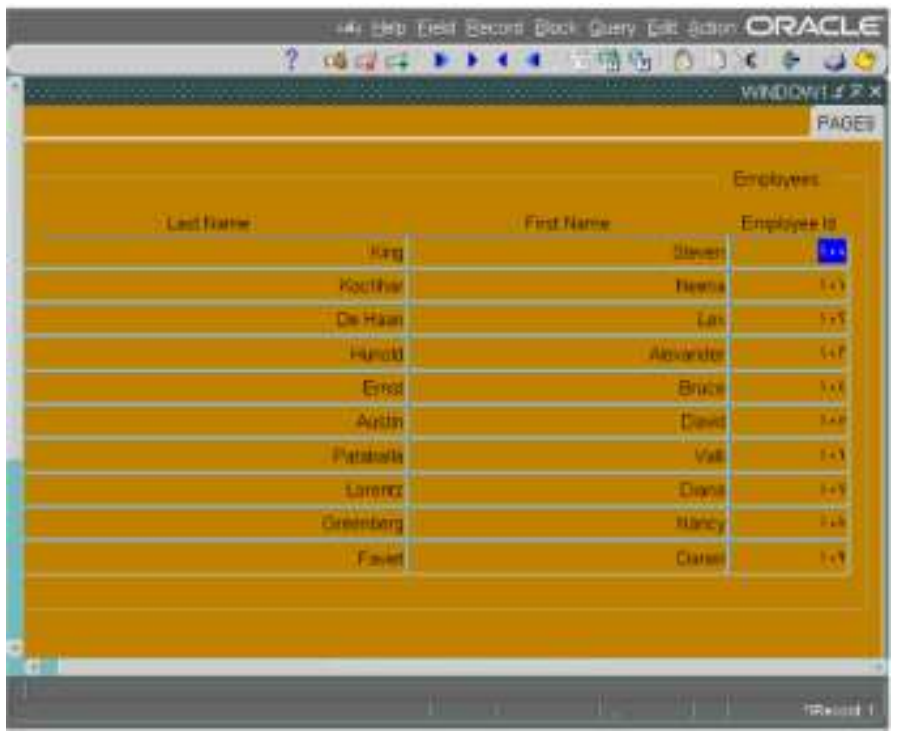

Fig 6: Employees Table in Form Builder

\section{ADMINISTRATION SYSTEM OBJECTS}

Objects that are used in administration systemin with oracle can be raise the performance of back data. This objects describe bellow: 


\section{Schema}

Schema objects are client-created frameworks that reference to the information in the system. The system backup numerous types of schema, the most important of which are tables and indexes. A schema object is one type of database object. Some objects such as profiles and roles, do not notification in schemas [IV].

\section{Index}

An index is an volitional data framework that we can activate on one or more columns of a table. Indexes can raise the performance of back data. When conversion a call, the database can use ready indexes to define the called archives efficiently. Indexes are helpful when sustem often request a specific information. Indexes are logically and physically separate of the data. Thus, we can delete and make indexes with no influence on the tables or other indexes [IV].

\section{Conclusions}

The administration system is interfacing database Oracle Form Builder software to easy interface between user and database and enhance performance and security. Companies use Oracle Form Builder for application development requiring the capabilities that MySQL does not offer such as it includes a procedural language to develop stored procedures, triggers, and functions, views. Design of administration system in client is made available to employees to assist them in the performance of their job duties.

\section{ACKNOWLEDGMENTS}

Our thanks to specializer who have contributed towards development of the paper.

\section{REFERENCES}

I. Marlene Theriault ,William Heney,1998,Publisher: O'Reilly.

II. P. Sai Prathap Pullagura, A. Gokilavani ,2014,Defeating SQL Injection on Preventing Run Time Attacks , The International Journal Of Science \& Technoledge.

III. White Paper, March 2004, OracleDatabase 10g:Administration Workshopl, First Edition.

IV. Lance Ashdown, Tom Kyte, 2015, Oracle Database concepts, 12c .Release1 (12, 1) E 4139613. 